\title{
IUMRS-ICEM-98 Will Meet in Cheju, Korea in August
}

The 4th International Conference on Electronic Materials (IUMRS-ICEM-98), chaired by Soon Ja Park (Seoul National University), will be held at Cheju, Korea during August 24-27, 1998. This is a continuation in the series of meetings held in Strasbourg, France (1992), Hsinchu, Taiwan (1994) and Boston, Massachusetts (1996). Since its inception in 1992, the ICEM has provided a forum focused on the areas of preparation, characterization, and application of electronic materials. IUMRS-ICEM98 will emphasize the latest developments in research areas of various electronic materials such as Si-based materials, compound semiconductors, electroceramics, display materials, magnetic materials, packaging, conducting polymer, and energy conversion materials. The meeting is organized by the Materials Research Society of Korea (MRS-K) under the auspices of the International Union of Materials Research Societies (IUMRS). English is the official language of the conference.

IUMRS-ICEM-98 consists of ten symposia. Symposium A on Silicon Processes will provide an interactive forum for discussion of research activities on $\mathrm{Si}$ processes such as advanced metallization, interconnection technologies, dielectric materials, epitaxial growth, thin films, deposition technologies, diffusion processes, photolithography, and etch processes. The physi$\mathrm{cal}$ and electrical properties of Si-based materials and the evaluation and characterization of Si processes will be addressed.

Compound semiconductors have been the subject of intensive study for applications in the field of photonics and electronics. The field is expanding in response to the ever-increasing demand for high-quality information technology and it is becoming ever more important to pay closer attention to the potential capabilities of these valuable materials, both scientifically and technologically. Symposium $B$ is designed to review and present recent advances and future prospects on the scientific and applications aspects based on compound semiconductors.

Electroceramics is expected to lead the development of electronic industries in the 21 st century, and in recent years, the importance of electroceramics has grown in the solid-state science. Symposium C on Electroceramics and Sensors will provide an interdisciplinary discussion and exchange of ideas on recent fundamental and advanced science and technology (S\&T) concerning various areas in electroceramics, including dielectrics and insulators, piezoelectric and pyroelectric materials, ceramic conductors, electro-optic ceramics, chemical and biosensors, and physical sensors.

Symposium D on Display Materials will focus on advances in materials and fabrication technology related to flatpanel displays (FPD) based on field emission, plasma, liquid crystal, electroluminescence, projection, and light-emitting diode. Materials include substrate and packaging materials as well as electronic materials for FPDs. Also, development in materials to meet the demanding needs of higher performance and to improve production efficiency will be discussed.

Symposium E on Magnetics will include all basic and applied S\&T related to magnetic material, including soft magnetic materials and applications, hard magnetic materials and applications, artificially structured materials, and magnetic recording.

Symposium F on Ferroelectric Thin Films will present a wide range of topics spanning from basic academic research to applied integration issues. These topics will cover fundamental materials studies, new growth methods, device and materials integration research, developments in designing and growing new materials, all involving epitaxial, polycrystalline, and nanocrystalline ferroelectric thin films. Many fast developing research areas, as well as memory technologies and very low loss electro-optical films, will also be presented.

Electronic packaging becomes very important for high performance, speed, density, and reliability of electronic systems. Packaging materials, design, interconnection, and assembly can break through the future electronics. Symposium G on Electronic Packaging will provide a forum to explore questions of materials, process, and reliability and also to promote technical exchange of advanced packaging.

Symposium $\mathrm{H}$ on the Surface, Interface, and Nanostructure of Materials will provide a forum for basic and applied research on surface, interface, and nanostructures. Various areas of surface physics and chemistry will be addressed, including discoveries in the topics of surface structure, electronic structure, nucleation and growth, catalysis, surface chemical reactions, and topics in understanding atomistic progresses, as well as new application of devices in nanometer-sized systems.

Strong demands are made to develop new materials and electronic devices for handling information. Polymer materials with a very short history compared to other materials in applications for electronics have potential to be designed and synthesized to perform as needed. The aim of Symposium I on Polymers for Electronics is to review the recent progress in development of functional polymers to be used in electronics.

Symposium J on Energy Conversion \& Storage Materials will focus on basic and applied research in various aspects of the development of new materials in energy conversion and storage systems. The following areas will be addressed: lithium-ion batteries, lithium-solid polymer electrolyte batteries, nickel-metal hydride batteries, metal/air batteries, solid polymer electrolyte fuel cells, solid oxide fuel cells, electrochemical capacitors, and thermoelectric materials.

The proceedings of ICEM'98 will be published in the Journal of Korean Physical Society (JKPS)

The registration fees are $\$ 450$ before May 31, 1998 (\$100 for students), and $\$ 500$ after May 31 (\$120 for students). The registration fee includes conference materials such as abstract books, admission to the technical sessions, welcome reception, coffee breaks, and the official excursion.

All inquiries regarding the meeting should be addressed to Prof. Shinhoo Kang, The Secretariat of IUMRS-ICEM-98, Materials Research Society of Korea, School of Materials Science and Engineering, Seoul National University, Seoul 151-742, Korea; phone 82-2-880-7167; fax 82-2-8841413; e-mail : icem98@gong.snu.ac.kr or icem98@plaza1.snu.ac.kr. More information can also be found at website http: //gong.snu.ac.kr/ icem98.

\section{MRS BULLETIN SEEKS IUMRS NEWS ON}

\author{
- Upcoming Meetings - Research News - Conference Reports Policy Issues - Important Technical Developments Educational Initiatives
}

MRS Bulletin, Materials Research Society, 506 Keystone Drive, Warrendale, PA 15086-7573 USA

E-mail: bulletin@mrs.org, Fax: 724-779-8313 
FALL MEETING
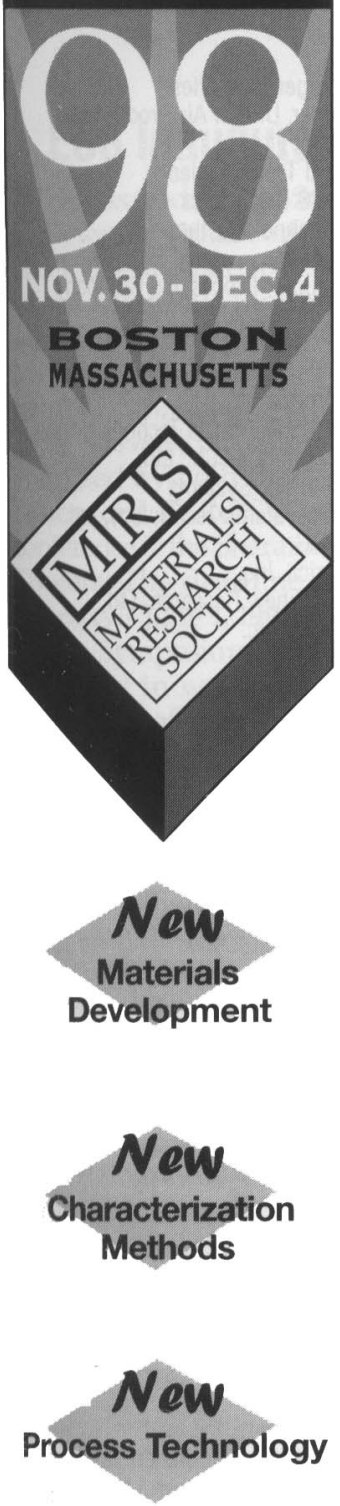

M R $\mathrm{S}$ Materials Research Society

For additional meeting intomation or to request a Cell for Papers booklet, a dotalled 1998 Fall Meeting Program, information on emposium tutorials, publlcations, the Exhibit, lab Center, or Symposium Asolstant positions, contact:

MRS Member Services 506 Keystone Drive Warrendale, PA 15086-7573 Telephone: 724-779-3003 Fax: $\quad 724-779-8313$ E-mall: info@mrs.org Web site: http:/www.mrs.org/

\section{Abstract Deadlines:}

In fairness to all potential authors, late abstracts will not be accepted.

June 8, 1998: for abstracts sent via fax or mail

June 22, 1998: for abstracts sent via the MRS Web site or e-mail

\section{Fall Meeting Symposia}

A: Polycrystalline Thin Films-

Processing-Structure-Property Relationships

B: Growth Instabilities and Decomposition During Heteroepitaxy

C: Surface and Interface Structure and Dynamics

D: Integration of Dissimilar Materials in Micro- and Optoelectronics

E: Film Growth and Processing Using Hyperthermal Beams

F: Microcrystalline and Nanocrystalline Semiconductors

G: GaN and Related Alloys

$\mathrm{H}: \quad$ Infrared Semiconductor Materials and Devices

I: III-V and SiGe Group IV Device/IC Processing Challenges for Commercial Applications

$\mathrm{J}: \quad$ Multiscale Modeling of Materials

K: Computation of Rates of Activated Processes

$\mathrm{L}: \quad$ Interaction of Phase and Defect Microstructures in Metallic Alloys

M: Fracture and Ductile vs Brittle BehaviorTheory, Modeling, and Experiment

$\mathrm{N}$ : Microstructural Processes in Irradiated Materials

O: Ferroelectric Thin Films VII

P: Magnetic Oxides and Oxide Devices

Q: High-Temperature Superconductors-Materials Challenges

R: Organic Electronic and Photonic Materials and Devices

S: Carbon Nanotubes, Fullerenes and Related Carbon Materials

T: Recent Progress in Optical Data Storage and Processing

U: Organics with Supramolecular Structure and Function
V: Solid Freeform and Additive Fabrication

$W$ : Dynamics in Small Confining Systems V

$X: \quad$ Frontiers of Materials Research

Y: Plasma Deposition and Treatment of Polymers

Z: Thermoelectric Materials-The Next Generation Materials for Small-Scale Refrigeration and Power Generation Applications

AA: Materials Science of Microelectromechanical System (MEMS) Devices

BB: Nonlithographic Methods for Organizing Materials into Functional Structures

CC: Combinatorial Chemistry and Materials Science

DD: Solid-State Chemistry of Inorganic Materials I|

EE: Solid-State lonics

FF: Advanced Catalytic Materials 1998

GG: Polymeric Materials-Drugs, Delivery and Devices

$\mathrm{HH}$ : Tissue Engineering

II: Advanced Materials, Coatings, and Biological Cues for Medical Implants

JJ: Materials in Space-Science, Technology, and Exploration

KK: High-Temperature-Ordered Intermetallic Alloys VIII

LL: Quasicrystals

MM: Bulk Metallic Glasses

NN: Aging of Engineered Systems with Focus on Aircraft

OO: Properties and Processing of Vapor-Deposited Coatings

PP: Recent Advances in Ceramic Matrix CompositesStructural Design, Fabrication, and Long-Term Use

QQ: Scientific Basis for Nuclear Waste Management XXII

RR: Workshop on Materials Education

\section{MRS 1998 FALL MEETING}

The MRS 1998 Fall Meeting will serve as a key forum for discussion of interdisciplinary leading-edge materials research from around the world. Various meeting formats—oral, poster, round table, forum and workshop sessions-are offered to maximize participation

\section{SYMPOSIUM TUTORIAL PROGRAM}

Available only to meeting registrants, the tutorials will concentrate on new, rapidly breaking areas of research and are designed to encourage the exchange of information by meeting attendees during the symposium.

\section{EXHIBIT}

A major exhibit encompassing the full spectrum of equipment instrumentation, products, software, publications, and services is scheduled for December 1-3 in the Boston Marriott and Westin Hotels convenient to the technical session rooms.

\section{PUBLICATIONS DESK}

A full display of over 530 books, plus videotapes and electronic databases, will be available at the MRS Publications Desks. Available at this meeting will be the MRS Symposium Proceedings from both the 1997 Fall and 1998 Spring Meetings, as well as the highly acclaimed Handbook of Modern Ion Beam Materials Analysis.
SYMPOSIUM ASSISTANT OPPORTUNITIES

Graduate students who plan to attend the 1998 Fall Meeting and are willing to assist in the symposium presentations by operating audio-visua equipment are encouraged to apply for a Symposium Assistant position. The student will receive a stipend toward expenses. After assisting in four half-day sessions, he or she will atso receive a waiver of the student registration fee and a complimentary one-year MRS membership commencing January 1, 1999. Application forms can be requested via e-mail: info@mrs.org; phone 724-779-3003; or fax 724-779-8313.

\section{JOB CENTER}

A Job Center for MRS meeting attendees will be open Tuesday through

Thursday during the 1998 Fall Meeting (location to be announced). For information, check the MRS Web site (http://www.mrs.org/) or contact MRS Member Services. 
ABB Extrel

Accurel-MAG (Materials Analysis Group)

Advanced Control Systems Corporation

Advanced Energy Industries, Inc.

Advanced Micro Devices, Inc.

AEA Technology

Aerospace Corporation

Aetrium, Inc.

AG Associates

Air Products and Chemicals, Inc.

AIXTRON, Inc.

Aldrich Chemical Company, Inc.

AlliedSignal, Inc.

Amptek, Inc.

AMRAY, Inc.

ANVAL

APD Cryogenics, Inc.

Applied Komatsu Technology

Applied Materials

Physical Vapor Deposition

Applied Materials

RTP Product Division

Argonne National Laboratory

Asahi Glass Co., Ltd

ASM

AST elektronik GmbH

ASTeX/Applied Science and

Technology, Inc

Baikowski International Corporation

Balzers Process Systems

Bede Scientific Incorporated

Bell Laboratories, Lucent Technologies

Bicron, Saint-Gobain Industrial

Ceramics, Inc.

BIOMET Incorporated

Blake Industries, Inc.

Brookhaven Instruments Incorporated

Brookhaven National Laboratory

Bruker Analytical X-ray Systems, Inc.

Bruker Instruments, Inc.

Burleigh Instruments, Inc

Cameca Instruments, Inc.

Candescent Technologies Corp.

Canon, Inc.

Capovani Brothers, Inc.

Carnegie Institution of Washington

CEA-LETI

Chemat Technology, inc

Chemipro Kasei Kaisha, Ltd.

Chichibu Onoda Cement Co., Ltd.

Chroma Technology Corp.

City Technology Limited

CNR-IMETEM

Coherent, Inc./Laser Group

Commonwealth Scientific Corporation

Consortium für Elektrochemische

Industrie $\mathrm{GmbH}$

Corning Incorporated

Cree Research, Inc.

CVC

Dainippon Screen Manufacturing Co., Ltd.

Danfysik ASS

DCA Instruments, Inc.

Denton Vacuum, Inc

Diamond Semiconductor Group, Inc.

Digital Instruments, Inc.

Digital Semiconductor (A Digital

Equipment Corporation)

Dow Chemical Company

Dow Corning Corporation

dpiX, a Xerox Company

DSM Research

Dupont Company, Central Research

and Development

Dytech Corporation, Ltd

Eastman Kodak Company

Eaton Corporation

Eaton Thermal Processing Systems

EDAX International

EG\&G Instruments, Inc.

EG\&G Ortec

Electric Power Research Institute (EPRI)

Elsevier Science Ltd.

EMCORE Corporation
Energy Conversion Devices, Inc.

E.0. Lawrence Berkeley Laboratory

EPI MBE Products Group

ESM Sottware

Charles Evans \& Associates

Evans East

Exxon Production Research Company

FEl Company

EA. Fischione Instruments, Inc.

Ford Motor Company

Freund Publishing House, Ltd.

Fuji Electric Co., Ltd.

Fujikin of America, Inc.

Fujitsu, Ltd.

Futaba Corp.

Gatan, Inc.

Gelest, Inc.

Genentech, Inc.

General Electric Company

General Motors

Research \& Development

GE Superabrasives

GMW Associates

Goodfellow Corporation

Gordon and Breach

Granville-Phillips Company

Hanil Cement Mfg., Co.

Headway Technologies, Inc.

Hewlett Packard Company

Network Measurement Division

Hewlett Packard Laboratories

High Voltage Engineering Europa B.V.

Hitachi, Ltd.

Hitachi Scientific Instruments

Hoechst Celanese Corporation

Advanced Technology Group

Hoechst Celanese Corporation

Separations Products Division

Hughes Research Laboratories

Huntington Mechanical Laboratories, Inc.

Hysitron, Inc

IBM Almaden Research Center

IBM Analytical Services

IBM Corporation

Thomas J. Watson Research Center

ICl Acrylics

IMES Co., Ltd.

Initiative Scientific Products

Inorgtech, Ltd.

Institut für Schicht und Ionentechnik (ISI)

Instron Corporation

Insulator Seal Inc.

Intel Corporation

International Specialty Products

Intevac

Ion Tech, Inc.

JCPDS-International Centre for

Diffraction Data

JEOL USA, Inc.

J.I.P. ELEC

Johnsen Ultravac

Johnson Controls, Inc.

Johnson \& Johnson Professional, Inc.

Johnson Matthey Electronics, Inc.

k-Space Associates, Inc.

Keithley Instruments, Inc.

Kimball Physics, Inc.

KLA-Tencor

Komag, Inc.

Komatsu Electronic Metals $\mathrm{C}_{0}$., Ltd.

Kratos Analytical, Inc.

Lake Shore Cryotronics, Inc.

Lambda Physik, Inc

Lambda Technologies, Inc.

Lawrence Livermore National Laboratory

Leica Inc.

Kurt J. Lesker Company

Leybold Systems GmbH

Leybold Vacuum Products, Inc.

Lloyd Technology Associates, Inc.

Lockheed Idaho Technologies Co.

Los Alamos National Laboratory

Luxel Corporation

Materials Research Corporation
Materials Research Group, Inc.

Matsushita Electric Industrial Co., Ltd

Matsushita Electronics Corporation

Mattson Technology, Inc

MDC Vacuum Products Corporation

MEL Chemicals

MEMC Electronic Materials, Inc.

Micrion Corporation

Micro Photonics, Inc.

Microwave Research Center

Mitsubishi Electric Semiconductor

Laboratories

Mitsubishi Silicon America

Mitsui-Toatsu Chemicals, Inc

MKS Instruments, Inc

MMR Technologies, Inc.

Mobil Technology Company

Molecular Imaging Corporation

Molecular Simulations, Inc

Morita Chemical Industries

Morton International, Inc.

Motorola

Advanced Products Research

Motorola

Phoenix Corporation Research

MVSystems, Inc.

n\&k Technology, Inc.

Nano Instruments, Inc

Nanophase Technologies Corporation

NanoPore, Inc.

National Electrostatics Corporation

National Renewable Energy Laboratory

National Semiconductor Corporation

National Technology Transfer Center

NEC Corporation

NEC Research Institute, Inc.

Neocera, Inc.

New Focus, Inc

Nichia Chemical Industries, Ltd.

Nikko Hitech International, Inc.

NORAN Instruments, Inc.

Noranda Advanced Materials

Nor-Cal Products, Inc.

Novellus Systems, Inc

NSA Nissei Sangyoi America, Ltd.

Oak Ridge National Laboratory

Oldham S.A. France

Omicron Associates

OnTrak Systems, Inc

Optics for Research

Osmic, Inc.

Oxford Cryosystems

Oxford Instruments America, Inc

Park Scientific Instruments

Pfeiffer Vacuum Technology, Inc.

Philip Morris Inc.

Philips Analytical

Philips Electron 0ptics

Physical Electronics

Plasma-Therm, Inc.

Plenum Publishing Corporation

Portland Cement Association

Praxair Surface Technologies

President Enterprises Co.

Princeton Gamma-Tech, Inc.

Princeton Measurements Corporation

Pure Tech, Inc.

Quad Group, Inc

Quantum Design, inc.

Renishaw PLC

Research and PVD Materials Corporation

RHK Technology, Inc.

Riber Division/ISA Inc

Rigaku/USA, Inc.

RIMCOF (R\&D Institute of Metals \&

Composites for Future Industries)

RJ Lee Instruments, Ltd.

R.M.D. Inc.

Rockwell International Science Center

Samsung Advanced Institute of Technology

Sandia National Laboratories

Sanyo Electric Co L Ltd.

Sanyo Vacuum Industries Co., Ltd.

Schlumberger Cambridge Research

Schlumberger Industries

Schumacher, Unit of Air Products \&

Chemicals

SCP Global Technologies

Screen DNS Electronics

Seagate Technology, Inc.

Sematech, Inc.

Semiconductor Processing Company

Semitool, Inc.

SensArray Corporation

SGS-Thomson Microelectronics

Sharp Corporation

Sharp Microelectronics Technology, Inc.

Shin-Etsu Handotai Co., Ltd.

Shining Surface Systems

SiGe Microsystems Technology, Inc.

Siemens AG

SKC America, Inc.

Smith \& Nephew Research, Ltd

SOITEC/USA, Inc.

Solarex

Solartron

SONY Corporation

South Bay Technology, Inc.

Southwire Company

Spire Corporation

Springer-Verlag New York, Inc.

Ssangyong Cement Company

STAIB Instruments, Inc.

Steag-AST Elektronik USA

StorMedia, Incorporated

Strem Chemicals, Inc

SULA Technologies

Sulzer Metco (US) Inc.

Sumitomo Electric Industries, Ltd.

Basic High Technology Laboratories

Sumitomo Electric Industries, L.td. 